\title{
Transconjunctival 25-gauge pars plana vitrectomy and internal limiting membrane peeling for chronic macular edema
}

This article was published in the following Dove Press journal:

Clinical Ophthalmology

29 June 2012

Number of times this article has been viewed

\section{Minhee Cho \\ Donald J D'Amico}

Weill Cornell Medical College, Department of Ophthalmology, New York, NY, USA
Correspondence: Donald J D’Amico

Weill Cornell Medical College,

Department of Ophthalmology,

I 305 York Ave, I Ith Floor,

New York, NY I002I, USA

$\mathrm{Tel}+\mathrm{I} 6469622220$

Fax + I 6469620600

Email djd2003@med.cornell.edu
Background: The purpose of this study was to investigate the visual and anatomic outcomes in patients with chronic macular edema who underwent 25 -gauge pars plana vitrectomy with internal limiting membrane peeling.

Methods: This study was a retrospective chart review of 24 eyes from 21 patients who underwent 25-gauge pars plana vitrectomy and indocyanine green-assisted internal limiting membrane peeling for chronic macular edema. Preoperative and postoperative spectral-domain optical coherence tomography (OCT) was examined for macular thickness and macular volume. Outcomes and variables were analyzed using the two-tailed $t$-test and Spearman's rank correlation coefficient.

Results: Twenty-four eyes from 11 men and 10 women of mean age 69 (range 55-84) years were included. Four patients (17\%) had chronic macular edema from uveitis, four (17\%) from retinal vein occlusion, and $16(67 \%)$ from diabetes. Mean visual acuity was 20/103 preoperatively and $20 / 87$ postoperatively $(P=0.55)$. Sixty-three percent of the eyes had improved vision $(47 \%$ better than 20/40), 21\% maintained the same vision, and $17 \%$ had worse vision. Forty-seven percent of improved eyes and $30 \%$ of total eyes gained more than two lines of visual acuity (range -9 to +7 lines). Mean macular thickness was $455 \mu \mathrm{m}$ preoperatively and $396 \mu \mathrm{m}$ postoperatively $(P=0.29)$. Mean macular volume was $7.9 \mathrm{~mm}^{3}$ preoperatively and $7.5 \mathrm{~mm}^{3}$ postoperatively $(P=0.51)$. The strongest predictor of postoperative visual acuity was initial visual acuity ( $\mathrm{r}=0.673, P=0.0003)$.

Conclusion: Even though a majority of patients had improved vision and decreased macular thickening after 25-gauge pars plana vitrectomy with internal limiting membrane peeling for chronic macular edema of various etiologies, the difference in visual acuity or macular thickening did not reach statistical significance.

Keywords: chronic macular edema, diabetes mellitus, internal limiting membrane peeling, 25-gauge vitrectomy, uveitis, vein occlusion

\section{Introduction}

Macular edema is one of the leading causes of vision loss in many retinal vascular diseases, such as diabetic retinopathy and retinal vein occlusion. Historically, the gold standard treatment for macular edema, especially of diabetic etiology, had been laser photocoagulation. ${ }^{1}$ Recently, the spectrum of available treatment options for macular edema has expanded greatly with the introduction of intravitreal antivascular endothelial growth factor and steroids. Both the BRAVO and CRUISE studies have demonstrated the efficacy of ranibizumab in the treatment of macular edema caused by branch and central retinal vein occlusion. ${ }^{2,3}$ The SCORE studies have also shown some degree of visual and anatomic improvement after treatment with intravitreal triamcinolone 
in similar patient populations. ${ }^{4,5}$ The READ-2 study showed the efficacy of intravitreal ranibizumab for diabetic macular edema. ${ }^{6}$ Intravitreal dexamethasone has been approved for the treatment of macular edema from uveitis and vein occlusions. ${ }^{7,8}$ However, macular edema in some patients recurs or remains refractory despite various pharmacologic treatments. For example, diffuse diabetic macular edema has been recognized to be less responsive to laser treatments and have shown mixed results with intravitreal treatments.

In addition to targeting the vascular permeability or inflammation associated with macular edema via pharmacologic means, some have proposed altering structural causes that may explain the persistence or recurrence of macular edema. Diabetic patients with posterior vitreous detachment have been shown to be less likely to develop macular edema. ${ }^{9}$ Traction at the vitreomacular interface has been hypothesized to contribute to macular edema in diabetes. Lewis et al demonstrated reduction in macular edema and improvement in visual acuity in diabetic patients with diffuse macular edema after pars plana vitrectomy; all these patients were found to have taut premacular hyaloid on clinical examination prior to vitrectomy. ${ }^{10}$ Peeling of internal limiting membrane during vitrectomy has also been reported to improve diabetic macular edema. ${ }^{11-15}$ The internal limiting membrane is thought to exert additional traction across the macula; it may also act as a scaffold for proliferating astrocytes that may contribute to the formation of preretinal membranes. ${ }^{11}$ Here we review the visual and anatomic outcomes for 24 eyes from 21 consecutive patients with chronic macular edema from various causes who underwent 25-gauge sutureless pars plana vitrectomy with internal limiting membrane peeling.

\section{Materials and methods}

This was a retrospective consecutive case series of patients who underwent microcannula-based, transconjunctival 25-gauge pars plana vitrectomy and internal limiting membrane peeling for chronic macular edema from January 2006 to June 2010 by a single surgeon (DJD) at the Weill Cornell Medical College Department of Ophthalmology. The study protocol was approved by the institutional review board. Inclusion criteria included patients with persistent macular edema (longer than 3 months) from any etiology with or without previous treatments undergoing 25-gauge pars plana vitrectomy (Accurus, Alcon Laboratories Inc, Fort Worth, TX) and membrane peeling assisted by indocyanine green (IC-Green, Akorn Inc, Lake Forest, IL). Medical records were reviewed for demographic information, medical and ocular history, complete ophthalmic examination findings, intraoperative findings, and postoperative complications. The presence of macular edema was confirmed by either slit lamp biomicroscopy or optical coherence tomography (OCT) using Topcon 3D-2000 (Topcon Medical Systems Inc, Oakland, NJ) or Heidelberg Spectralis HRA + OCT (Heidelberg Engineering Inc, Vista, CA) spectral-domain OCT.

Only the OCT scans performed using the Heidelberg spectral-domain OCT were included in the data analysis to maintain consistency in manual segmentation and measurements. All scans were performed using an approximately $6 \mathrm{~mm} \times 4.5 \mathrm{~mm}$ raster grid with 16 frames of images averaged per line (high-speed locked automated real-time averaging mode). All thickness and volume measurements were carried out using the default software in the OCT machine. Segmented layers defining the internal limiting membrane (preoperatively) or neurofiber layer surface (postoperatively) and retinal pigment epithelium layer were checked and adjusted manually by one of the investigators (MC) to make the most accurate thickness measurements. The macular thickness value was derived from the average thickness of a $1 \mathrm{~mm}$ circle around the central fovea based on the Early Treatment Diabetic Retinopathy Study (ETDRS) grid. Macular volume was derived from average volume measurements of $6 \mathrm{~mm}$ circle around the central fovea also based on the ETDRS grid. Preoperative and postoperative ocular findings, including best-corrected visual acuity (BCVA), OCT, macular thickness, and macular volume, were compared using the two-tailed Student's $t$-test. Snellen visual acuity was converted to the logarithm of the minimal angle of resolution ( $\log$ MAR) units for statistical analysis. Preoperative factors such as glycosylated hemoglobin $\left(\mathrm{HbA}_{1 \mathrm{c}}\right)$, duration of macular edema, preoperative macular thickness, macular volume, and presence or absence of posterior hyaloid attachment that may be associated with the visual and anatomic outcomes were evaluated using Spearman's rank correlation coefficient.

All surgeries were performed by a single surgeon (DJD). A three-port transconjunctival 25-gauge vitrectomy system was used for all cases. Complete removal of the posterior hyaloid was ensured using either the vitrectomy cutter or a soft-tipped cannula. The infusion was clamped and a dilute solution of indocyanine green $(0.5 \%, 5 \mathrm{mg} / \mathrm{mL})$ was placed on the retinal surface and allowed to remain for a few seconds, at which point the infusion was turned back on and the indocyanine green aspirated from the eye. 25-gauge internal limiting membrane forceps (Grieshaber Revolutions 
DSPS, Alcon Laboratories Inc) were used to peel the internal limiting membrane in all cases. Once all the cannulae were removed, pressure was maintained over each sclerotomy site for a few minutes. All patients were examined on postoperative day 1 and at various times afterwards, depending on patient recovery. Patients were monitored for complications including wound leak, hemorrhage, retinal tears or detachments, glaucoma, choroidal detachment, endophthalmitis, and cystoid macular edema. OCT was performed at various times after the operation and the final measurements were used from the OCT scans performed nearest to the final follow-up.

\section{Results}

Twenty-four eyes of 11 men and 10 women of mean age 69 (range 55-84) years were included. Preoperative characteristics are listed in Table 1. Four patients (17\%) had chronic macular edema from uveitis, four (17\%) from retinal vein occlusion, and 16 (67\%) from diabetes. The etiology of uveitis included acute retinal necrosis, retained lens fragment, birdshot chorioretinopathy, and idiopathic anterior uveitis. The mean $\mathrm{HbA}_{1 \mathrm{c}}$ was $7.3 \%$ (range 5.4\%-11.1\%) in the diabetic patients. The mean duration of macular edema from all causes was 18.9 (range 2-108) months. Sixty-seven percent of the eyes had previously been treated with macular laser and $42 \%$ with intravitreal injections $(70 \%$ bevacizumab, $60 \%$ triamcinolone) ranging from one to seven injections per patient.

Mean preoperative BCVA was 0.71 (Snellen equivalent $20 / 103$, range $20 / 40$ to counting finger vision). Mean preoperative intraocular pressure was 13 (range 8-20) $\mathrm{mmHg}$. Mean preoperative central macular thickness was $455 \pm 39$ (range 252-708) $\mu \mathrm{m}$. Preoperative mean macular volume was $7.9 \pm 0.5$ (range 5.3-10.6) $\mathrm{mm}^{3}$. One patient (case 24 in Table 1) with macular edema from concurrent diabetes and central vein occlusion underwent intraoperative fluid air exchange with $10 \% \mathrm{C} 3 \mathrm{~F} 8$ gas to tamponade retinal hemorrhage (preoperative visual acuity counting fingers, final postoperative visual acuity counting fingers). A second patient (case 19 in Table 1) with macular edema from retained lens material underwent enlargement of one of the sclerotomies for use of a 20-gauge phacofragmatome (preoperative visual acuity 20/63, final postoperative visual acuity 20/60). A third patient (case 9 in Table 1) with diabetic macular edema received an intraocular triamcinolone injection (preoperative visual acuity 20/125, final postoperative visual acuity 20/125).
Mean postoperative BCVA improved to 0.64 (Snellen equivalent $20 / 87, P=0.55$, range $20 / 20$ to counting fingers). Mean postoperative day 1 intraocular pressure was $10 \pm 0.9$ (range 2-18) mmHg. Sixty-three percent of the eyes $(n=15)$ had improved vision ( $47 \%$ better than $20 / 40), 21 \%$ maintained same vision, and $17 \%$ had worse vision. Fortyseven percent of improved eyes and 30\% $(n=7)$ of total eyes gained more than two lines of visual acuity (range -9 to +7 lines). Eighty-three percent of the eyes had improved macular thickness after vitrectomy. Sixty percent of the eyes with improved macular thickness had improvement in visual acuity (Figure 1A and B). Two patients had increased thickening after pars plana vitrectomy (Figure 1C and D). Sixty-seven percent had improved macular volume after vitrectomy and $63 \%$ of these eyes had improvement in visual acuity. Three eyes had a worse visual outcome despite improvement in macular thickness; two of three eyes had a disrupted subfoveal inner/outer segment (IS/OS) junction on the OCT (cases 16 and 18) and one developed subretinal fibrosis (Figure 1E and F, case 10).

The mean postoperative macular thickness changed from $455 \pm 39 \mu \mathrm{m}$ to $396 \pm 38 \mu \mathrm{m}$ (range $239-677 \mu \mathrm{m}, P=0.29$ ). The mean postoperative macular volume changed from $7.9 \mathrm{~mm}^{3}$ to $7.5 \pm 0.4 \mathrm{~mm}^{3}$ (range $5.6-10.5 \mathrm{~mm}^{3}, P=0.52$ ). Patients with a disrupted IS/OS junction on the preoperative OCT had worse postoperative BCVA compared with those with an intact IS/OS junction, although the difference was not statistically significant (mean 20/200 versus 20/75, $P=0.46$ ). Presence of cystic edema versus noncystic retinal thickening did not influence the postoperative BCVA $(P=0.79)$. Eyes with predominantly outer retinal layer cystic edema (below outer plexiform layer including subretinal fluid) tended to have a worse visual outcome compared with those with predominantly inner retinal layer cystic edema (above inner nuclear layer, mean $20 / 125$ versus $20 / 60, P=0.25$ ). When the different etiologies for macular edema were analyzed separately, all groups had improvement in vision and macular thickness and volume, but none of these improvements reached statistical significance (Table 2).

The eyes with more than two lines of visual acuity improvement tended to have a shorter duration of chronic macular edema (10 months versus 21.7 months, $P=0.2$ ), lower $\mathrm{HbA}_{1 \mathrm{c}}(6.85 \%$ versus $7.62 \%, P=0.29)$, and decreased postoperative macular thickness $(331 \mu \mathrm{m}$ versus $409 \mu \mathrm{m}$, $P=0.44$ ), although the difference did not reach statistical significance. Eyes with posterior hyaloid attached to the macula preoperatively (confirmed on OCT) tended to 
Table I Preoperative and postoperative characteristics of patients with chronic macular edema who underwent 25-gauge pars plana vitrectomy with indocyanine green-assisted internal limiting membrane peel

\begin{tabular}{|c|c|c|c|c|c|c|}
\hline Etiology of ME & Case no & Age & Gender & $\mathbf{H b A}_{\mathrm{lc}}$ & ME duration (months) & Previous treatment for $\mathrm{ME}$ \\
\hline \multirow[t]{16}{*}{ DM } & 1 & 70 & $\mathrm{~F}$ & 7 & 12 & Avastin* inj \\
\hline & 2 & 72 & $\mathrm{~F}$ & 6.4 & 7 & Focal laser \\
\hline & 3 & 57 & M & 6.2 & & Focal/steroid/avastin inj \\
\hline & 4 & 57 & M & 6.2 & & Focal/steroid \\
\hline & 5 & 84 & $\mathrm{~F}$ & 10.9 & & Focal laser \\
\hline & 6 & 69 & $\mathrm{~F}$ & II.I & 6 & Focal laser \\
\hline & 7 & 63 & M & & 10 & Focal/avastin \\
\hline & 8 & 64 & $\mathrm{~F}$ & 6.7 & 108 & Focal \\
\hline & 9 & 77 & M & 5.6 & 60 & Focal/avastin/steroid \\
\hline & 10 & 68 & M & 7.4 & 4 & None \\
\hline & 11 & 55 & M & 8 & 6 & Focal \\
\hline & 12 & 76 & M & & 14 & None \\
\hline & 13 & 76 & M & & 2 & None \\
\hline & 14 & 67 & $\mathrm{~F}$ & 7 & 24 & Focal/avastin/steroid \\
\hline & 15 & 65 & M & 6.8 & 15 & Focal \\
\hline & 16 & 65 & $M$ & 6.8 & & Focal \\
\hline \multirow[t]{4}{*}{ Uveitis } & 17 & 63 & $M$ & & & None \\
\hline & 18 & 67 & $M$ & & 4 & None \\
\hline & 19 & 75 & M & & 15 & None \\
\hline & 20 & 70 & $\mathrm{~F}$ & & & None \\
\hline \multirow[t]{3}{*}{ BRVO } & 21 & 76 & $M$ & & 24 & Focal/avastin \\
\hline & 22 & 73 & $\mathrm{~F}$ & & 6 & Focal/steroid \\
\hline & 23 & 69 & $\mathrm{~F}$ & 6.7 & & Focal/steroid \\
\hline CRVO/DM & 24 & 72 & $\mathrm{~F}$ & 9.1 & 5 & Focal/avastin \\
\hline
\end{tabular}

Total mean

Note: *Avastin, bevacizumab.

Abbreviations: ME, macular edema; $\mathrm{HbA}_{1 \mathrm{c}}$, glycosylated hemoglobin; BCVA, best-corrected visual acuity; MT, macular thickness; MV, macular volume; DM, diabetes mellitus; F, female; M, male, CF, counting fingers; BRVO, branch retinal vein occlusion; CRVO, central retinal vein occlusion; preop, preoperative; postop, postoperative; inj, injection.

have a worse visual and anatomic outcome compared with those who had a detached posterior hyaloid preoperatively (visual acuity $20 / 125$ versus $20 / 80, P=0.54$; macular thickness $481 \mu \mathrm{m}$ versus $335 \mu \mathrm{m}, P=0.10$; macular volume $8.55 \mathrm{~mm}^{3}$ versus $\left.6.74 \mathrm{~mm}^{3}, P=0.05\right)$. The strongest predictor of postoperative visual acuity was initial visual acuity $(\mathrm{r}=0.673, P=0.0003)$. Other factors were not significantly associated with postoperative BCVA (Table 3). Postoperative OCT was performed 7 months after the surgery on average (range 2-25 months). Mean final intraocular pressure was $13 \pm 0.7$ (range 8-25) $\mathrm{mmHg}$. Mean time to best postoperative BCVA was 3 months (range 1 day to 14 months). Mean postoperative follow-up was 11 (range 2.5-32) months. The power for comparison of preoperative and postoperative visual acuity reached $9 \%$ due to a small sample size.
There were no cases of retinal detachment, endophthalmitis, or persistent hypotony/choroidal detachment postoperatively. Two patients underwent cataract extraction. One patient developed vitreous hemorrhage and underwent repeat pars plana vitrectomy for removal of hemorrhage.

\section{Discussion}

Our study demonstrates that 25 -gauge sutureless vitrectomy with indocyanine green-guided internal limiting membrane peeling is a safe option that may help maximize visual potential in patients with chronic macular edema from diabetes, uveitis, or vein occlusions. Spectral-domain OCT was utilized for outcome measurements in some patients. The majority of our patients had improved visual and anatomic outcomes postoperatively, even though the difference was not statistically significant. Fifteen $(63 \%)$ of the 24 eyes 


\begin{tabular}{|c|c|c|c|c|c|c|c|}
\hline $\begin{array}{l}\text { Preop Snellen } \\
\text { BCVA }\end{array}$ & $\begin{array}{l}\text { Postop Snellen } \\
\text { BCVA }\end{array}$ & $\begin{array}{l}\text { Change in lines } \\
\text { of Snellen BCVA }\end{array}$ & $\begin{array}{l}\text { Preop MT } \\
(\mu \mathrm{m})\end{array}$ & $\begin{array}{l}\text { Postop MT } \\
(\mu \mathrm{m})\end{array}$ & $\begin{array}{l}\text { Preop MV } \\
\left(\mathrm{mm}^{3}\right)\end{array}$ & $\begin{array}{l}\text { Postop MV } \\
\left(\mathrm{mm}^{3}\right)\end{array}$ & $\begin{array}{l}\text { Time to BCVA } \\
\text { (months) }\end{array}$ \\
\hline $20 / 50$ & $20 / 20$ & +4 & & & & & 3 \\
\hline $20 / 500$ & $20 / 200$ & +4 & & & & & 3.5 \\
\hline $20 / 40$ & $20 / 40$ & 0 & & & & & 3 \\
\hline $20 / 80$ & $20 / 25$ & +5 & & & & & 5.5 \\
\hline $20 / 50$ & $20 / 40$ & +1 & & & & & 3.5 \\
\hline $20 / 70$ & $20 / 80$ & -0.5 & & & & & 14 \\
\hline $20 / 200$ & $20 / 150$ & +0.1 & & & & & 5.5 \\
\hline $20 / 160$ & $20 / 160$ & 0 & & & & & 3 \\
\hline $20 / 125$ & $20 / 125$ & 0 & 358 & 493 & 5.28 & 6.22 & 1 \\
\hline $20 / 200$ & $\mathrm{CF}$ & -9 & 655 & 385 & 8.35 & 6.34 & 0.03 \\
\hline $20 / 200$ & $20 / 100$ & +3 & 527 & 262 & 10.64 & 8.39 & 4 \\
\hline $20 / 50$ & $20 / 40$ & +1 & 406 & 352 & 7.98 & 7.7 & 3 \\
\hline $20 / 80$ & $20 / 80$ & 0 & 382 & 336 & 8.25 & 7.02 & I \\
\hline $20 / 100$ & $20 / 80$ & +1 & 543 & 605 & 7.29 & 8.84 & 0.03 \\
\hline $20 / 125$ & $20 / 80$ & +2 & 500 & 400 & 9.05 & 8.48 & $\mathrm{I}$ \\
\hline $20 / 40$ & $20 / 50$ & -1 & 419 & 336 & 8.54 & 8.61 & I \\
\hline $20 / 70$ & $20 / 70$ & 0 & 252 & 239 & 5.66 & 5.76 & 2 \\
\hline $20 / 63$ & $20 / 125$ & -4 & 327 & 306 & 7.69 & 6.48 & 4 \\
\hline $20 / 63$ & $20 / 60$ & +0.2 & 708 & 677 & 10.46 & 10.47 & 2 \\
\hline $20 / 200$ & $20 / 40$ & +7 & & & & & I \\
\hline $20 / 80$ & $20 / 60$ & +1.2 & 381 & 356 & 5.9 & 5.58 & 3.5 \\
\hline $20 / 60$ & $20 / 60$ & 0 & & & & & 3 \\
\hline $20 / 60$ & $20 / 40$ & +2 & & & & & 2 \\
\hline CF & CF & 0 & & & & & 4 \\
\hline $\begin{array}{l}\text { Preop } \\
\text { logMAR }\end{array}$ & $\begin{array}{l}\text { Postop } \\
\text { logMAR }\end{array}$ & & Preop MT & Postop MT & Preop MV & Postop MV & $\begin{array}{l}\text { Time to BCVA } \\
\text { (months) }\end{array}$ \\
\hline $0.71 \pm 0.08$ & $0.64 \pm 0.09$ & & $454.83 \pm 38.97$ & $395.58 \pm 38.30$ & $7.92 \pm 0.50$ & $7.49 \pm 0.43$ & $3 \pm 0.57$ \\
\hline$P=0.549$ & & & $P=0.29$ & & $P=0.517$ & & \\
\hline
\end{tabular}

had improved vision; $47 \%$ of those eyes had better than 20/40 vision and more than two lines of improvement on the Snellen visual acuity chart. The patients who had lower vision postoperatively (17\%) suffered from permanent anatomic changes, such as fibrosis and disrupted photoreceptor junctions secondary to chronic edema.

Several variables were associated with the final visual outcome, but only the level of preoperative visual acuity reached statistical significance $(P=0.0003)$. Subgroup analysis demonstrated that patients with more than two lines of improvement in vision tended to have a shorter duration of macular edema, lower $\mathrm{HbA}_{1 \mathrm{c}}$, and a thinner postoperative macular thickness. Patients with $\mathrm{HbA}_{1 \mathrm{c}}<7$, preoperative macular thickness $<400$, preoperative macular volume $<8$, and preoperative detachment of the posterior hyaloid also tended to have a better visual outcome. The etiology of chronic macular edema did not influence the final visual outcome.

Internal limiting membrane peeling has been used as an effective adjunct in the treatment of a variety of macular pathologies, including macular hole, epiretinal membrane, macular edema, and vitreomacular traction. ${ }^{16,17}$ In patients with diabetic macular edema, pars plana vitrectomy is postulated to remove both the tractional forces and growth factors that cause an increase in vascular permeability and to improve the oxygenation of the retina. Additional peeling of the internal limiting membrane at the time of pars plana vitrectomy as a treatment for refractory macular edema or a primary treatment is theorized to help further by removing any tangential tractions and residual cortical vitreous, improving movement of fluid into the vitreous, and by inhibiting the reproliferation of fibrous astrocytes. ${ }^{11}$ 

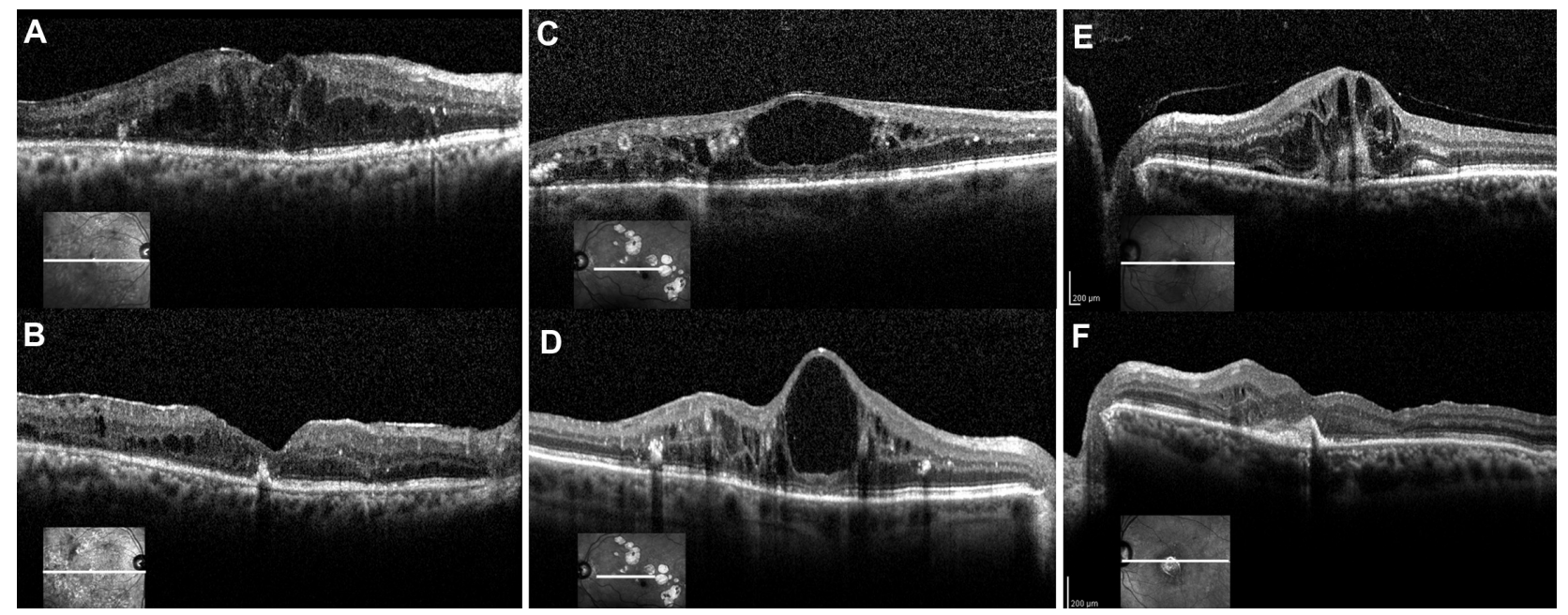

Figure I (A) A 55-year-old man with chronic macular edema from proliferative diabetic retinopathy, status post focal laser treatment (case II in Table I). Preoperative vision was 20/200. The preoperative spectral-domain OCT shows cystic edema mostly in the outer nuclear layer. The macular thickness measured $527 \mu \mathrm{m}$. (B) Postoperative

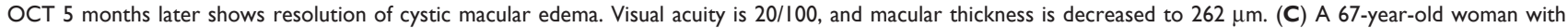
chronic macular edema from nonproliferative diabetic retinopathy, status post focal laser, intravitreal bevacizumab and triamcinolone injections (case 14 in Table $\mathrm{I}$ ). Preoperative vision was 20/100. The preoperative spectral-domain OCT shows an attached posterior hyaloid, a large cystoid space, and cystic edema, mostly in the outer plexiform layer. The inner/outer segment junction is intact. Macular thickness measured $543 \mu \mathrm{m}$. (D) Postoperative spectral-domain OCT 5 months later shows worsening of the central cystoid space. Central foveal thickness increased to $605 \mu \mathrm{m}$, but vision improved to 20/80. (E) A 68-year-old man with chronic macular edema from nonproliferative diabetic retinopathy without previous treatment (case I0 in Table I). Preoperative vision was 20/200. The preoperative spectral-domain OCT shows an attached posterior hyaloid and cystic edema in the inner and outer plexiform layers as well as evidence of trace subretinal fluid. Central foveal thickness measured $655 \mu \mathrm{m}$. (F) Postoperative spectral-domain OCT 8 months later shows resolution of macular edema (central foveal thickness $385 \mu \mathrm{m}$ ), but subretinal fibrosis is evident. The inner/ outer segment junction is attenuated subfoveally. Visual acuity is decreased to counting finger vision.

Abbreviation: OCT, optical coherence tomography.

However, pars plana vitrectomy with internal limiting membrane peeling for patients with chronic diabetic macular edema has shown mixed results. ${ }^{11,13-19}$ Most of these studies utilized a 20 -gauge vitrectomy system and used fluorescein angiography as a measure of the anatomic outcome whereas our study used 25 -gauge vitrectomy, and used OCT for the main analysis. Improvement of BCVA and reduction of macular thickness on OCT have been demonstrated following vitrectomy and internal limiting membrane peeling for diffuse diabetic macular edema without vitreomacular traction evident on OCT. ${ }^{15-28}$ Others have shown that in the absence of vitreomacular traction, vitrectomy with membrane peeling fails to improve visual acuity. ${ }^{18,29,30}$ In our study, patients with detached posterior hyaloid preoperatively tended to have a better visual and anatomic outcome; thus, preoperative vitreomacular traction does not appear to be necessary for the decision to operate on patients with chronic macular edema. The type of macular edema, whether cystoid or diffuse, and the preoperative status of the outer retinal layers on OCT have been reported to affect the visual outcome. ${ }^{31}$ In our study population, the presence of cystic edema versus diffuse noncystic retinal thickening did not influence the postoperative BCVA. However, the eyes with predominantly outer retinal layer cystic edema (below outer plexiform layer including subretinal fluid) tended to have a worse visual outcome compared with those with predominantly inner retinal layer cystic edema (above inner nuclear layer). Although no reports have shown this effect, fluid that is present closer to the photoreceptor layer may have a greater effect on vision.

Some studies have suggested that decreased foveal thickness in chronic macular edema does not consistently lead to improvement in visual outcome. ${ }^{18,25,30}$ In our study, only $63 \%$ of those with improved macular edema had improvement in vision. This may be related to multiple factors, such as the chronicity of macular edema (19 months in duration on average in our study) resulting in irreversible cellular damage that cannot yet be detected on OCT, disruption of the photoreceptor layers, or formation of subretinal fibrosis ( $\mathrm{n}=2$, cases 10 , 16 , and 18). Patients with a longer duration of macular edema tended to have a worse visual outcome. Individual cases showed variability, attesting to the possibility that there is a wide individual range of the time window wherein macular edema causes irreversible changes. Moreover, patients with a disrupted IS/OS junction on preoperative OCT tended to have worse postoperative BCVA compared with those with an intact IS/OS junction. However, the sample size was too small to make a definitive conclusion. Moreover, only eyes that underwent Heidelberg Spectralis OCT scans were 


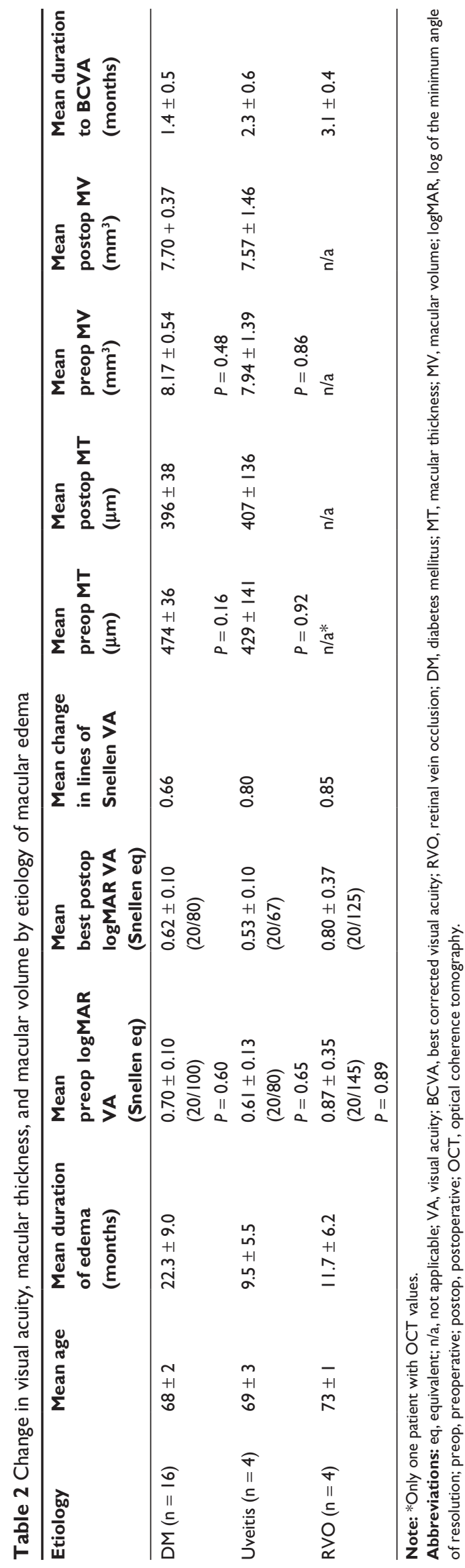

Table 3 Spearman's rank correlation coefficient for various factors

\begin{tabular}{|c|c|c|}
\hline & Correlation coefficient & $P$ value \\
\hline $\begin{array}{l}\text { Preop BCVA versus } \\
\text { postop BCVA }\end{array}$ & 0.673 & 0.0003 \\
\hline $\begin{array}{l}\text { Postop BCVA versus } \\
\text { preop macular thickness }\end{array}$ & 0.004 & 0.99 \\
\hline $\begin{array}{l}\text { Postop BCVA versus } \\
\text { preop macular volume }\end{array}$ & 0.071 & 0.83 \\
\hline $\begin{array}{l}\text { Postop BCVA versus } \\
\text { postop macular thickness }\end{array}$ & 0.011 & 0.97 \\
\hline $\begin{array}{l}\text { Postop BCVA versus } \\
\text { postop macular volume }\end{array}$ & -0.27 & 0.39 \\
\hline $\begin{array}{l}\text { Postop BCVA versus } \\
\text { macular edema duration }\end{array}$ & -0.274 & 0.29 \\
\hline $\begin{array}{l}\text { Postop BCVA versus } \\
\mathrm{HbA}_{\mathrm{Ic}}\end{array}$ & 0.092 & 0.73 \\
\hline
\end{tabular}

Abbreviations: Preop, preoperative; BCVA, best-corrected visual acuity; postop, postoperative; $\mathrm{HbA}_{1 \mathrm{c}}$, glycosylated hemoglobin.

included in the final data analysis $(\mathrm{n}=12,50 \%)$, and this may have affected the final outcome.

Data on the use of pars plana vitrectomy with or without internal limiting membrane peeling for chronic macular edema secondary to uveitis are also conflicted. ${ }^{32-36}$ It has been reported that $21 \%-52 \%$ of patients with uveitis have clinically significant macular edema causing a decrease in visual acuity. ${ }^{37}$ Persistent reduction in visual acuity was found in $74 \%$ of patients despite topical and systemic antiinflammatory treatments. ${ }^{32}$ Chronic inflammation from uveitis may cause similar thickening of the internal limiting membrane as seen in diabetic macular edema, impeding the outflow of fluid into the vitreous cavity. In our study, improvement was seen in macular thickness after pars plana vitrectomy with internal limiting membrane peeling, but this did not necessarily correlate with a significant improvement in vision, probably owing to the chronicity of the disease and pre-existing macular damage.

Data on the use of pars plana vitrectomy with or without internal limiting membrane peeling in branch or central retinal vein occlusion are variable. ${ }^{38-40}$ Pars plana vitrectomy alone for macular edema from retinal vein occlusion may help by reducing the number of permeability factors like vascular endothelial growth factor inside the vitreous cavity. ${ }^{41}$ Internal limiting membrane peeling in retinal vein occlusion is theorized to reduce macular edema by stimulating gliosis that leads to contraction of the retinal layers and a decrease in the extracellular spaces, better diffusion of blood and fluid from the retina into the vitreous cavity essentially by reversing a "compression syndrome" abnormality, removal of growth factors, and improved oxygenation of retinal layers. ${ }^{38,39,42}$ A study by Park et al 
showed that improvement in visual acuity after pars plana vitrectomy with internal limiting membrane peeling reached significance only in a perfused central retinal vein occlusion group and not in an ischemic central retinal vein occlusion group. ${ }^{43}$ In our study, we had three patients with branch retinal vein occlusion who either maintained or improved visual acuity. We only had one patient with central retinal vein occlusion who presented with a vision of counting fingers. A natural history study of central retinal vein occlusion demonstrated that patients presenting with less than $20 / 200$ vision had an $80 \%$ chance of either maintaining or deteriorating visual acuity at the final visit. ${ }^{44}$ This may be due to macular ischemia or optic nerve atrophy affecting visual recovery. In our patient with central retinal vein occlusion, subretinal fibrosis was evident on the final OCT, limiting the potential for visual improvement.

This study had several limitations, including a small sample size, a small number of cases for each individual subgroup, a retrospective study design, and a lack of control cases. Although the mean visual acuity, macular thickness, and volume improvement did not reach statistical significance, it is possible that a higher powered study may have shown a significant difference. In our study population, different morphologies on OCT and a few preoperative patient factors showed a tendency towards certain visual and anatomic outcomes. With a larger controlled study, significant differences may have manifested. Despite these shortcomings, the current study demonstrates that for patients with refractory and/or persistent macular edema despite nonsurgical treatment, small-gauge vitrectomy with internal limiting membrane peeling may help them reach their maximum visual potential.

\section{Acknowledgment}

This study was supported in part by an unrestricted grant from Research to Prevent Blindness Inc, to DJD. The material in this paper was presented as part of an invited lecture for the Club Jules Gonin Symposium at the European Society of Ophthalmology meeting, Geneva, Switzerland, June 6-9, 2011.

\section{Disclosure}

The authors report no conflicts of interest in this work.

\section{References}

1. The effect of intensive treatment of diabetes on the development and progression of long-term complications in insulin-dependent diabetes mellitus. The Diabetes Control and Complications Trial Research Group. N Engl J Med. 1993;329(14):977-986.
2. Campochiaro PA, Heier JS, Feiner L, et al. Ranibizumab for macular edema following branch retinal vein occlusion: six-month primary end point results of a Phase III study. Ophthalmology. 2010;117(6):1102-1112.

3. Brown DM, Campochiaro PA, Singh RP, et al. Ranibizumab for macular edema following central retinal vein occlusion: six-month primary end point results of a phase III study. Ophthalmology. 2010;117(6):1124-1133.

4. Scott IU, Ip MS, Van Veldhuisen PC, et al. A randomized trial comparing the efficacy and safety of intravitreal triamcinolone with standard care to treat vision loss associated with macular Edema secondary to branch retinal vein occlusion: the Standard Care vs Corticosteroid for Retinal Vein Occlusion (SCORE) study report 6. Arch Ophthalmol. 2009;127(9):1115-1128.

5. Ip MS, Scott IU, VanVeldhuisen PC, et al. A randomized trial comparing the efficacy and safety of intravitreal triamcinolone with observation to treat vision loss associated with macular edema secondary to central retinal vein occlusion: the Standard Care vs Corticosteroid for Retinal Vein Occlusion (SCORE) study report 5. Arch Ophthalmol. 2009;127(9):1101-1114.

6. Nguyen QD, Shah SM, Khwaja AA, et al. Two-year outcomes of the ranibizumab for edema of the macula in diabetes (READ-2) study. Ophthalmology. 2010;117(11):2146-2151.

7. Williams GA, Haller JA, Kuppermann BD, et al. Dexamethasone posterior-segment drug delivery system in the treatment of macular edema resulting from uveitis or Irvine-Gass syndrome. Am J Ophthalmol. 2009;147(6):1048-1054.

8. Haller JA, Bandello F, Belfort R Jr, et al. Randomized, shamcontrolled trial of dexamethasone intravitreal implant in patients with macular edema due to retinal vein occlusion. Ophthalmology. 2010;117(6):1134-1146.

9. Nasrallah FP, Jalkh AE, Van Coppenolle F, et al. The role of the vitreous in diabetic macular edema. Ophthalmology. 1988;95(10):1335-1339.

10. Lewis H, Abrams GW, Blumekranz MS, Capo RV. Vitrectomy for diabetic macular traction and edema associated with posterior hyaloidal traction. Ophthalmology. 1992;99(5):753-759.

11. Gandorfer A, Messmer EM, Ulbig MW, Kamplik A. Resolution of diabetic macular edema after surgical removal of the posterior hyaloid and the inner limiting membrane. Retina. 2000;20(2): 126-133.

12. Avci R, Kaderli B, Avci B, et al. Pars plana vitrectomy and removal of the internal limiting membrane in the treatment of chronic macular oedema. Graefes Arch Clin Exp Ophthalmol. 2004;242(10): $845-852$.

13. Kamura Y, Sato Y, Isomae T, Shimada H. Effects of internal limiting membrane peeling in vitrectomy on diabetic cystoid macular edema patients. Jpn J Ophthalmol. 2005;49(4):297-300.

14. Patel JI, Hykin PG, Schadt M, Luong V, Fitzke F, Gregor ZJ. Pars plana vitrectomy with and without peeling of the inner limiting membrane for diabetic macular edema. Retina. 2006;26(1):5-13.

15. Rosenblatt BJ, Shah GK, Sharma S, Bakal J. Pars plana vitrectomy with internal limiting membranectomy for refractory diabetic macular edema without a taut posterior hyaloid. Graefes Arch Clin Exp Ophthalmol. 2005;243(1):20-25.

16. Abdelkader E, Lois N. Internal limiting membrane peeling in vitreoretinal surgery. Surv Ophthalmol. 2008;53(4):368-396.

17. Morris R, Kuhn F, Witherspoon CD. Hemorrhagic macular cysts. Ophthalmology. 1994;101(1):1.

18. Hartley K, Smiddy W, Flynn HW Jr, Murray T. Pars plana vitrectomy with internal limiting membrane peeling for diabetic macular edema. Retina. 2008;28(3):410-419.

19. Thomas D, Bunce C, Moorman C, Laidlaw DA. A randomised controlled feasibility trial of vitrectomy versus laser for diabetic macular oedema. Br J Ophthalmol. 2005;89(1):81-86.

20. Figueroa MS, Contreras I, Noval S. Surgical and anatomical outcomes of pars plana vitrectomy for diffuse nontractional diabetic macular edema. Retina. 2008;28(3):420-426. 
21. Dillinger P, Mester U. Vitrectomy with removal of the internal limiting membrane in chronic diabetic macular oedema. Graefes Arch Clin Exp Ophthalmol. 2004;242(8):630-637.

22. Kimura T, Kiryu J, Nishiwaki H, et al. Efficacy of surgical removal of the internal limiting membrane in diabetic cystoid macular edema. Retina. 2005;25(4):454-461.

23. Yamamoto T, Hitani K, Sato Y, Yamashita H, Takeuchi S. Vitrectomy for diabetic macular edema with and without internal limiting membrane removal. Ophthalmologica. 2005;219(4):206-213.

24. Yanyali A, Nohutcu AF, Horozoglu F, Celik E. Modified grid laser photocoagulation versus pars plana vitrectomy with internal limiting membrane removal in diabetic macular edema. Am JOphthalmol.2005;139(5): 795-801.

25. Kumar A, Sinha S, Azad R, Sharma YR, Vohra R. Comparative evaluation of vitrectomy and dye-enhanced ILM peel with grid laser in diffuse diabetic macular edema. Graefes Arch Clin Exp Ophthalmol. 2007; 245(3):360-368.

26. Recchia FM, Ruby AJ, Carvalho Recchia CA. Pars plana vitrectomy with removal of internal limiting membrane in the treatment of persistent diabetic macular edema. Am J Ophthalmol. 2005;139(3):447-454.

27. Massin P, Duguid G, Erginay A, Haouchine B, Gaudric A. Optical coherence tomography for evaluating diabetic macular edema before and after vitrectomy. Am J Ophthalmol. 2003;135(2):169-177.

28. Shimonagono Y, Makiuchi R, Miyazaki M, Doi N, Uemura A, Sakamoto T. Result of visual acuity and foveal thickness in DME after vitrectomy. Jpn J Ophthalmol. 2007;51(3):204-209.

29. Shah SP, Patel M, Thomas D, Aldington S, Laidlaw DA. Factors predicting outcome of vitrectomy for diabetic macular edema: results of a prospective study. Br J Ophthalmol. 2006;90(1):33-36.

30. Hoerauf H, Brüggemann A, Muecke M, et al. Pars plana vitrectomy for diabetic macular edema: internal limiting membrane delamination vs posterior hyaloid removal. A prospective randomized trial. Graefes Arch Clin Exp Ophthalmol. 2011;249(7):997-1008.

31. Inoue M, Morita S, Watanabe Y, et al. Preoperative inner segment/outer segment junction in spectral-domain optical coherence tomography as a prognostic factor in epiretinal membrane surgery. Retina. 2011;31(7): 1366-1372.

32. Dugel PU, Rao NA, Ozler S, Liggett PE, Smith RE. Pars plana vitrectomy for intraocular inflammation-related cystoid macular edema unresponsive to corticosteroids. A preliminary study. Ophthalmology. 1992;99(1):1535-1541.

33. Verbraeken $H$. Therapeutic pars plana vitrectomy for chronic uveitis: a retrospective study of the long-term results. Graefes Arch Clin Exp Ophthalmol. 1996;234(5):288-293.
34. Tranos P, Scott R, Zambarajki H, Ayliffe W, Pavesio C, Charteris DG The effect of pars plana vitrectomy on cystoid macular oedema associated with chronic uveitis: a randomised, controlled pilot study. Br J Ophthalmol. 2006;90(9):1107-1110.

35. Gutfleisch M, Spital G, Mingels A, Pauleikhoff D, Lommatzsch A, Heiligenhaus A. Pars plana vitrectomy with intravitreal triamcinolone: effect on uveitic cystoid macular oedema and treatment limitations. Br J Ophthalmol. 2007;91(3):345-348.

36. Wiechens B, Nolle B, Reichelt JA. Pars plana vitrectomy in cystoid macular edema associated with intermediate uveitis. Graefes Arch Clin Exp Ophthalmol. 2001;239(7):474-481.

37. Zimmerman PL. Pars planitis and other intermediate uveitis. In: Yanoff M, Duker JS, editors. Ophthalmology. St Louis, MO: Mosby; 1999.

38. Mandelcorn MS, Nrusimhadevara RK. Internal limiting membrane peeling for decompression of macular edema in retinal vein occlusion: a report of 14 cases. Retina. 2004;24(3):348-355.

39. Decroos F, Shuler RK, Stinnett S, Fekrat S. Pars plana vitrectomy, internal limiting lembrane peeling, and panretinal endophotocoagulation for macular edema secondary to central retinal vein ccclusion. Am J Ophthalmol. 2009:147(4):627-633.

40. Arai M, Yamamoto S, Mitamura Y, Sato E, Sugawara T, Mizunoya S. Efficacy of vitrectomy and internal limiting membrane removal for macular edema associated with branch retinal vein occlusion. Ophthalmologica. 2009;223(3):172-176.

41. Noma H, Funatsu H, Mimura T, Eguchi S, Shimada K. Visual acuity and foveal thickness after vitrectomy for macular edema associated with branch retinal vein occlusion: a case series. BMC Ophthalmol. 2010;10:11-17.

42. Furino C, Ferrari TM, Boscia F, et al. Combined radial optic neurotomy, internal limiting membrane peeling, and intravitreal triamcinolone acetonide for central retinal vein occlusion. Ophthalmic Surg Lasers Imaging. 2005;36(5):422-425.

43. Park DH, Kim IT. Long-term effects of vitrectomy and internal limiting membrane peeling for macular edema secondary to central retinal vein occlusion and hemiretinal vein occlusion. Retina. 2010;30(1):117-124.

44. The Central Vein Occlusion Study Group. Natural history and clinical management of central retinal vein occlusion. Arch Ophthalmol. 1997;115(4):486-491.
Clinical Ophthalmology

\section{Publish your work in this journal}

Clinical Ophthalmology is an international, peer-reviewed journal covering all subspecialties within ophthalmology. Key topics include: Optometry; Visual science; Pharmacology and drug therapy in eye diseases; Basic Sciences; Primary and Secondary eye care; Patient Safety and Quality of Care Improvements. This journal is indexed on

\section{Dovepress}

PubMed Central and CAS, and is the official journal of The Society of Clinical Ophthalmology (SCO). The manuscript management system is completely online and includes a very quick and fair peer-review system, which is all easy to use. Visit http://www.dovepress.com/ testimonials.php to read real quotes from published authors. 